\title{
O BOM BÁRBARO E OUTRAS HISTÓRIAS
}

\author{
EUNÍCIA BARROS BARCELOS FERNANDES ${ }^{1}$ \\ $P R W, B R A S I L$
}

\begin{abstract}
RESUMO: O Pós Segunda Guerra acentuou críticas à razão moderna, redimensionou as relações entre os povos e construiu uma conceitual defesa da diferença nunca antes imaginada. No Brasil, a década de 1950 significou um avanço nas discussões e nas ações em prol do nacionalismo e da modernização. A partir da análise de representações públicas do período, tais como artigos de revistas de grande circulação - O Cruzeiro -, depoimentos de intelectuais, criação de cursos, de museus e mesmo do Parque Indígena do Xingu, o presente artigo defende esse momento como chave para a compreensão de atuais representações acerca dos indígenas, bem como de relações entre indigenas e não-indígenas no país. Argumenta que os novos contextos reconfiguraram antigos sentidos, estabelecendo simultaneamente a atualização de estereótipos, bem como a exigência de sua revisão.
\end{abstract}

PALAVRAS-CHAVE: Indígenas, Representação, 1950

\begin{abstract}
The post-Second War period accentuated criticism of modern reason, redimensioned relations between peoples and built a conceptual defense of difference never imagined before. In Brazil, the 1950s meant a breakthrough in discussions and actions in favor of nationalism and modernization. Based on the analysis of public representations of the period, such as articles of major circulation magazines - O Cruzeiro -, testimonies of intellectuals, the creation of courses, museums and even the Xingu Indigenous Park, the present article defends this moment as key to the comprehension of present representations about the indigenous people, as well as the relations between indigenous and non-indigenous people in the country. Arguing that the new contexts have reconfigured old meanings, establishing simultaneosly the updating of stereotypes, as well as the requirement for their revision.
\end{abstract}

KEYWORDS: Indigenous, Representation, 1950

\footnotetext{
${ }^{1}$ Pós doutora em Ensino de História pela Universidade Federal de Minas Gerais (2014) e Doutora em História Social pela Universidade Federal Fluminense (2001). Atualmente é professora de História e coordenadora pedagógica do Colégio e Curso PRW em Petrópolis, Rio de Janeiro. E-mail: euniciaf@yahoo.com.br
} 
Espaço Ameríndio

"Uma das mais fortes emoções que o papel impresso já me
proporcionou, devo-a ao cidadão do mundo, Jean Manzon.
Era uma fotografia, e representava um guerreiro Xavante
de arco esticado, a seta apontada para o céu, pontaria
alçada contra o avião cuja sombra negra Ihe aparecia ao
lado. Além de toda a força plástica de quadro tão belo, havia
ainda um elemento dramático, eterno, naquele flagrante.
Era o próprio coração bárbaro do Brasil, enfrentando o
mundo, o choque inicial do homem primitivo contra os
engenhos mais modernos da civilização, - era assombroso
constatar que o selvagem não se apavorava, que sozinho e
nu no meio da selva enfrentava a espantosa ave de ferro
carregada sabe Deus de que mistério e de que inimigos."

(QUEIROZ, 1956)

\section{Introdução}

O depoimento de Raquel de Queiroz e a imagem de Jean Manzon condensam e articulam uma compreensão de como a década de 1950 percebia os indígenas. Elas abrem oportunidade de investigarmos mudanças que, acredito, reconfiguraram o imaginário, estabelecendo novos parâmetros para as relações entre indígenas e não-indígenas e que ainda estão presentes no século XXI.

Começo pela emoção. A imagem do fotógrafo e as palavras da escritora são discursos que carregam o drama entre o avanço da modernização e o valor atribuído aos povos originários como pilares da nacionalidade. A imagem e as palavras guiam o olhar e o contato do avião com os indígenas gera assombro, espanto e beleza. O leitor que vive aquele momento, não escapa das sensações.

A perspectiva do historiador identifica esses materiais como representações daquele mundo, analisando as informações que trazem. A fotografia, por exemplo, independente do conteúdo que carrega, é ela mesma evidência da tecnologia, não apenas por ser máquina fotográfica, mas máquina portátil que permite a imagem aérea, ou seja, a forma com que foi realizada é indício de outra tecnologia, o avião. Não só. Para que avião e fotógrafo estivessem ali condições foram necessárias, como o avanço da imprensa - que ia da melhoria dos periódicos até sua multiplicação, o que sustentava o investimento de enviar repórteres aos confins do Brasil - e as ações governamentais - que pretendiam a modernização do país. Já as palavras da escritora são evidência de valores e entendimentos compartilhados pela sociedade, onde o indígena está associado à barbárie, 
o avião a uma modernidade implacável e a simultaneidade entre eles expõe tensões históricas.

Imagem e texto constroem um enfrentamento entre o indígena desnudo e a sombra do avião, um enfrentamento entre o 'coração bárbaro' e o 'engenho moderno', entre a emoção frágil e a razão forte, mas também entre a coragem diante do receio - identificado nos 'mistérios' e nos 'inimigos'. Essa dualidade verbalizada atualiza a tensão entre o 'primitivo' e o 'civilizado', presente no contato entre indígenas e não-indígenas ao longo dos séculos.

Já se pode materializar a mudança de imaginário em andamento, pois atualizar não é mimetizar nem repetir, mas garantir que antigos elementos tenham significado em novas realidades, o que implica reconfiguração: as antigas noções deslocadas das relações originais e rearrumadas segundo critérios, no caso, do contexto dos anos 50.

No período colonial, adjetivação recorrente para os indígenas era bárbaro e inconstante, criando uma aura de violência e desconfiança que deixava portugueses alertas, na espera de serem atacados a qualquer momento e até devorados. No período imperial o termo bárbaro se manteve vigoroso, mas muitas vezes associou-se à ideia de primitivo e inferior, articulado às referências científicas da época. "Catequese e civilização" era o projeto que os transformaria e, em breve, o Brasil teria apenas brasileiros. Caso resistissem, seriam exterminados porque a resistência era sinônimo da selvageria da qual deveriam ser retirados. É verdade que no Império do Brasil o movimento indianista criara uma positivação, mas apenas para 'o índio', para a alegoria que inventava uma base para a nação, indígena inexistente, figura estereotipada e sem etnia, que teria morrido, ficado no passado. As pinturas, os versos, xilogravuras e medalhas produzidas naquela época não eram de indígenas vivos - já que esses eram ameaça ao avanço territorial e à modernização -, mas uma releitura interessada daqueles que teriam lutado ao lado de portugueses e iniciado o que era o Império.

Mesmo na República, quando o governo - pressionado - institui o órgão voltado à preservação física de indígenas - o SPILTN (depois SPI) -, o imaginário de ferocidade nativa não foi eliminado, pois a imprensa da época trazia notícias trágicas das expedições, em que funcionários eram mortos a flechadas e bordoadas, ratificando a selvageria e o medo.

Na década de 1950, o texto de Rachel de Queiroz e a imagem de Jean Manzon realizam algo inusitado: mesmo com arco e flecha empunhados, a percepção não é de ameaça, ao contrário, é quase compaixão, pois ele é traduzido em coração, emoção e coragem diante da imbatível modernização que o eliminaria. De algoz à vítima, pois a superioridade daquele que está literalmente no alto elimina o medo, transformando o indígena em ingênuo, defendendo-se do que era visto como inevitável. Vivo, mas acuado. O olhar muda, tornando possível uma positivação distinta daquela do Indianismo.

Não é um pequeno detalhe. Até pouquíssimo tempo, arcos e flechas legitimavam extermínio e agora, através dessas representações, o indígena 
vivo em pose de ameaça não era temido e merecia elogios. O que haveria mudado? E o que mudaria?

Rachel e Manzon se apropriaram do mundo e o apresentaram, carregando cada qual sua bagagem, seus porquês. Não há imparcialidade, mas interpretação. O olhar do fotógrafo recorta, destaca, apaga, prioriza, lapida, ou seja, ele elabora uma aproximação, uma visão entre as muitas possíveis. Jean Manzon poderia fazer uma foto distante, de toda a aldeia, ou só do indígena, ocultando a sombra do avião, ou ainda poderia contrastar o avião à oca - dois objetos - e não a um ser humano, enfim, poderia produzir muitos outros entendimentos e emoções a partir de sua lente. Do mesmo modo, Raquel de Queiroz poderia ter escolhido outra entre as muitas (e belas) imagens produzidas pelos fotógrafos que foram estimulados a ir ao 'coração do Brasil' e exibi-lo aos brasileiros², assim como poderia se expressar por outras palavras.

Suas escolhas, no entanto, destacaram algumas articulações que podem ser chaves para compreendermos o que se passava. Assim, o objetivo é investigar conexões entre a atitude nacionalista e modernizadora do governo brasileiro, a diversidade e outros valores consolidados no pós Segunda Guerra Mundial, o avanço da ciência dentro das políticas públicas e os indígenas. Aposto que o diálogo e contraste entre essas informações foi o solo das alterações que criaram um horizonte bem diverso daquele que até então fora possível para as representações e auto representações indígenas, considerando que as representações são relacionais e uma ação provoca uma reação.

A análise de materiais do período - como a revista O Cruzeiro, depoimentos de intelectuais, iniciativas acadêmicas e museais e até a criação do Parque Indígena do Xingu - sugere os anos 50 como um divisor de águas nas percepções sobre os indígenas, alterando paradigmas anteriores e referendando padrões que permanecem atuais e norteiam as representações e práticas de não-indígenas. Acredito ter sido um momento de virada onde antigos estereótipos ganharam novas funções sociais e passaram a conviver, pela primeira vez, com críticas que ameaçaram sua continuação.

No Brasil da década de 50, a euforia pela experiência democrática, pela aquisição de bens de consumo, pelo desenvolvimento dos meios de comunicação (MELLO \& NOVAIS, 1998) se misturava àquela de ver o cotidiano familiar de Xavantes, indígenas tidos como violentos e assassinos desde a criação do SPI. Tocar as páginas de uma revista com fotos - vistas como realidades incontestes - acionava encantamentos que podiam seguir no caminho do exotismo, num deslumbramento do diferente, ou no da ciência, ativando os conceitos que o crescimento da antropologia disponibilizava, mas que, de um modo ou de outro, colidiam com a ideia da simples eliminação dos nativos. Ideias de preservação cultural somaram-se

\footnotetext{
${ }^{2}$ Destaco aqui não somente a ação de outros fotógrafos voltados ao tema indígena, mas aqueles que buscaram o negro, o sertanejo, enfim, tipos distantes do parâmetro urbano e industrializado e que, naquele momento, estereotipava não apenas o nacional, mas alimentava o discurso - e as ações - de modernização.
} 
à de preservação do indivíduo e em escala antes inimaginada, justo pelo dinamismo da imprensa.

A possibilidade de compreendermos o que estava em pauta, entretanto, exige perspectiva sendo necessário instituir um repertório que permita a comparação entre representações daquele momento e outras anteriores. Através da história, viabilizar o entendimento de como elementos antigos se conectaram a novos, promovendo 0 entusiasmo no 'conhecimento do índio' e tornando-o sinônimo de 'Brasil' que estava sendo 'descoberto', metáfora nada inocente e que revigorava sentidos de origem da nação.

Invisto no "modo como em diferentes lugares e momentos uma determinada realidade social é construída, pensada, dada a ler" (CHARTIER, 1990 p.16). Expor representações sociais sobre indígenas é mostrar que as referências foram construídas dentro de circunstâncias históricas específicas e vividas por grupos igualmente específicos, ainda que tenham sido apresentadas como verdades inerentes à condição indígena. As visões do 'bom' ou do 'mau' índio, por exemplo, estão presentes em nosso cotidiano, assim como as associações entre os indígenas e o 'nacional'. O que não podemos perder de vista é que tais visões se estabeleceram (e estabelecem) historicamente, a partir de interesses e posicionamentos dentro de contextos particulares.

\section{Representações coloniais}

No século XVII, Albert Eckhout pintor e botânico holandês, fez parte dos intelectuais que estudaram a América portuguesa durante o domínio de Maurício de Nassau. Sua produção imagética foi intensa, exibindo fauna e flora, mas se destacaram (e ainda se destacam) as pinturas feitas em tamanho natural para apresentar os tipos que habitavam a colônia. Formando casais, Eckhout construiu uma galeria de alteridades, pois o pintor não retratou os europeus: apenas tupis, tapuias, africanos e mestiços se transformaram em telas. São muitas as possibilidades reflexivas sobre tais obras, mas comentarei exclusiva e simplificadamente as imagens femininas identificadas pelo autor como índias tupi e tapuia, o que garante dados para o exercício comparativo.

Muitas são as oposições entre as duas indígenas ${ }^{3}$ : enquanto a tupi aparece semivestida e tendo ao fundo uma casa-grande com fazenda e trabalhadores também indígenas, a tapuia está nua e tem atrás de si a mata e um festim canibalístico. As duas carregam cestos, mas é significativa a diferença do que eles contêm: enquanto no cesto da índia tupi é possível ver produtos agrícolas, no da tapuia há partes de um corpo humano - pé e mão.

\footnotetext{
${ }^{3}$ Observo que meus comentários serão genéricos e direcionados ao objetivo do texto. Silenciarei sobre desdobramentos importantes para a análise das imagens que merecem artigo exclusivo.
} 
Isolada, essa última poderia indicar recolhimento de partes do morto para cerimônia fúnebre, mas a leitura é relacional e o conteúdo humano é indicação do canibalismo. Evidencia-se para a tapuia a natureza bruta, a animalidade indomável, num distanciamento do propósito colonizador, inclusive, podendo ser-lhe uma ameaça à vida; já na índia tupi todos as características constroem uma leitura de docilidade e acomodação aos interesses do colonizador, sendo expoente desse arranjo o fato dela ser retratada com uma criança ao colo, mimese da Madona, transmitindo simultaneamente placidez da maternidade, religiosidade e reprodutibilidade de mão-de-obra.

No jogo de aproximações e distanciamentos promovido pelas imagens, estabelece-se um perfil de indígenas aliados e de indígenas inimigos, segundo olhos europeus. Sob tal premissa, a simples nomeação de certos grupos como tapuias justificaria uma ação belicosa por parte dos europeus. Por outro lado, a imagem da índia tupi construía o imaginário de diálogo possível, explicitando a efetiva participação dos nativos no processo colonizador. Podemos dizer, portanto, que aquelas imagens balizavam as ações de colonizadores. Mas é preciso cuidado, pois a dicotomia manifesta nas telas nunca foi absoluta: indígenas amigos poderiam se tornar inimigos e vice-versa. A chamada 'inconstância da alma selvagem' (VIVEIROS DE CASTRO, 2011) brincava com as balizas genéricas, mantendo um permanente clima de suspeição.

Esse enquadramento neerlandês alinhava-se a conhecidos textos de portugueses católicos, especialmente jesuítas, criando uma intertextualidade que, à época, auxiliava na interpretação de uns e de outros. E auxilia agora na construção da perspectiva que permite a identificação de alterações efetivadas ao longo do tempo e na década de 1950.

No século XVII é impossível descolar a religião do imaginário acerca dos indígenas. De maneira prática, a cristianização foi o meio escolhido pela coroa portuguesa para evitar assaltos indígenas aos povoadores, causando destruição e morte, ou seja, a religião seria um meio de domesticação daqueles seres bravios. Não só. A identidade católica era tão importante para os portugueses que, a seus olhos, o batismo era rito suficiente para que o indígena se tornasse vassalo de seu rei. Ser cristianizado era per si atributo de familiaridade com o mundo europeu e definidor de alianças. A informação é capital, pois os termos amigo/inimigo ou bravo/manso continuarão a ser utilizados séculos depois - mas como dentro de outro contexto histórico, as associações e potencialidades serão diversas. A secularização, o desenvolvimento de teorias científicas evolutivas e a constituição no século XIX de um estado-nação independente que ansiava firmar seu território deslocarão os critérios avaliativos da religiosidade, alterando as justificativas para identificar uns e outros como amigos ou inimigos, bons ou maus.

As avaliações de colonizadores inauguraram um modo de ver e marcaram indelevelmente o senso comum nas representações sobre indígenas, onde epítetos como bárbaro e selvagem se repetiram e repetem 
à exaustão. Mas é preciso sair da generalidade e identificar que os tais termos carregaram significados diferenciados, conectando-se à verdade de cada época, seja religião, seja ciência.

As palavras são também históricas, os termos não significam a mesma coisa em qualquer tempo e espaço ou dito por qualquer pessoa. É imperativo compreender a existência de camadas interpretativas, de discursos que, parecendo semelhantes, dizem coisas diversas e conduzem a estratégias diferenciadas.

\section{Império do Brasil}

Tal como no período colonial, o Império do Brasil entrecruzou representações sociais e políticas governamentais, uma sustentando a outra, ainda que não se possa esquecer que não há uniformidade nelas ou entre elas. A sociedade pode exibir (e frequentemente exibe) variadas representações que se colocam em disputa, ora ganhando uma, ora outra, inclusive na definição das políticas efetuadas.

Em meados do século XIX, o imperador D. Pedro II se tornou frequentador das reuniões do Instituto Histórico e Geográfico Brasileiro, chegando a encomendar trabalhos sobre indígenas aos intelectuais do Instituto, como foi o caso de A confederação dos Tamoios, escrita por Gonçalves de Magalhães. Essa participação e solicitação são indícios de uma preocupação do monarca - compartilhada por homens da época - em assegurar o reinado através de uma identidade nacional. É nesse momento que o movimento romântico firma seus princípios através de artes que apresentam o índio (na generalidade que o termo traz) como elemento identificador do Brasil. O guarani foi tema literário e de ópera, assim como os tamoios foram festejados no ensaio de Magalhães e em tela de Rodolfo Amoedo. Presente nos signos da realeza (na murça imperial), nas artes (romances, telas, litogravuras e esculturas), o índio tornou-se representação do Brasil. Ao invadir a imprensa, a representação atravessará o século e se manterá presente mesmo depois de proclamada a república.

Entretanto, a representação celebrada era a de um índio idealizado e pretérito. Idealizado por não se referir a nenhuma etnia de fato, sendo um aglomerado de estereótipos; pretérito por aparecer como lembrança positiva de um tempo distante - o início da colonização -, mas que não existia mais. Era uma alegoria e como tal tanto descaracterizava a multiplicidade de grupos indígenas existentes como silenciava sobre os frequentes enfrentamentos entre autoridades provinciais e indígenas, que se viam expulsos ou coagidos pela presença cada vez maior de não-indígenas em seus territórios.

O século XIX, portanto, combinou de modo paradoxal um elogio ao índio - fazendo dele alicerce da nação - e ações de 'catequese e civilização' que procuravam eliminá-lo cultural ou fisicamente. Interessante é identificar 
que cada uma dessas ações - elogio e extermínio - foi capitalizada no uso recorrente dos termos Tupi e Botocudo. Os primeiros eram os indígenas mansos, aqueles sobre os quais se dizia da coragem e valentia e que serviam para qualificar o nacional, mas que haviam ficado no passado colonial; os segundos eram os indígenas bravos, tapuias, aqueles sobre os quais se atestava uma 'indomável ferocidade' e contra os quais se guerreava ou se buscava civilizar (KODAMA, 2005).

A comparação entre os nomes das pinturas de Eckhout e os termos do século XIX não é desprezível. Ainda que a experiência histórica entre os dois períodos tenha sido distinta no que tange ao contato entre indígenas e nãoindígenas, há, nos dois momentos, uma interpretação simplificada e maniqueísta, onde os Tupi aparecem como bons e os outros - Tapuia ou Botocudo - como maus. Deste modo, pode-se pensar num diálogo entre a interpretação antiga e uma atual realidade, onde o Império se apropria do maniqueísmo do período colonial, quando a valorização de um grupo se fazia na depreciação de outro, mantendo a tensão entre positivo e negativo na qualificação dos indígenas em geral.

Esse diálogo, porém, é uma atualização e, como tal, acepções diversas entraram em jogo. Não havia mais colônia portuguesa, mas um Império novo que desejava conquistar seu lugar no concerto das nações, demandando para si uma história e uma singularidade: mesmo quando valorizado, o indígena jamais se tornaria emblema nacional português como o Indianismo fazia com o Brasil. Por outro lado, enquanto na colônia se poderia atribuir a indígenas o papel de 'muralhas dos sertões', fazendo deles estratégia territorial diante de outras coroas, o Império que se esforçava para garantir seu território o fazia no avanço sobre povos nativos, dizimando-os. 0 passado poderia abrigar a figura do índio heroico e forte, mas o presente exigia que ele fosse deslocado de suas terras. Nas artes, podia-se encontrar uma consagração, com o índio estereótipo sendo louvado, mas no cotidiano era preciso atender aos interesses de cafeicultores. Palavras iguais diziam coisas diferentes, pois o Tupi da colônia era o indígena vivo que empreendia ao lado do português, o Tupi do Império era um índio morto e pretérito.

Única legislação do Império voltada aos indígenas vivos, o Regulamento de 1845 , apresentou medidas que iam no sentido contrário ao elogio: uma política de expulsão de suas terras; obrigatórias conversão e instrução primária; treinamento em ofícios mecânicos e incentivo à lavoura. Em outras palavras, o ideal nacional estava posto no índio alegoria, morto como $O$ Último Tamoio de Rodolfo Amoedo, enquanto o indígena vivo, aquele com quem se convivia, era constrangido a deixar de ser índio. Não satisfazia mais um indígena cristianizado, imediatamente absorvido à Coroa portuguesa. Ele agora deveria, de modo laico, deixar seus costumes para se tornar brasileiro.

\section{República}


A alegoria do Império será incorporada pela república e os periódicos frequentemente expuseram o índio fictício como o Estado ou a Nação brasileira na Primeira República. Inclusive, deve-se supor uma multiplicação substantiva desse imaginário, pois justo nesse período há um aumento de jornais e revistas circulantes, dos quais o serviço de assinatura permitia que os confins do Brasil acessassem o que se discutia na capital. Quantos teriam a chance de ver os quadros com indígenas de Vítor Meireles? Quantos assistiram à ópera de Carlos Gomes? Quantos leram José de Alencar? O movimento indianista construiu uma referência, mas ela circulava em ambientes mais restritos, fazendo sentido para menos pessoas. Com a intensificação da imprensa em fins do XIX e início do XX, e, especialmente, com a melhoria técnica que ampliou o uso da ilustração nos jornais e revistas, a circunstância foi outra: a ampliação garantiu que mesmo analfabetos e estrangeiros pudessem incorporar a associação. Nas propagandas de produtos farmacêuticos, nas caricaturas sobre a política interna e externa, os indígenas apareciam para a sociedade constituindo um lugar comum discursivo, mas com a devida distância que a alegoria concede. Ninguém precisava lidar efetivamente com indígenas.

A circulação de fotografias de indígenas, constituindo outro tipo de representação, aconteceu na divulgação da Comissão Rondon e, depois, com a divulgação das ações do Serviço de Proteção aos Indígenas e de Localização de Trabalhadores Nacionais. A familiaridade da alegoria contrastou com o distanciamento das fotos que, na exibição da nudez e demais características, reforçavam a visão de que eram homens primitivos que precisavam evoluir. A evolução e o progresso - do forte positivismo da época - se casavam com o propósito de civilizar os indígenas para sua incorporação no todo nacional.

Os indígenas eram um estrato social concebido como
transitório, futuramente incorporáveis à categoria dos
trabalhadores nacionais. Para o SPILTN, as populações
classificáveis enquanto indígenas não eram povos dotados
de história própria, de tradições que os singularizariam
entre si sendo a comunidade nacional brasileira deles
distinta: eram brasileiros pretéritos. (LIMA, 1995, p.120).

E a leitura do primitivo entrelaçou-se ao clima de violência e de barbárie quando apareceram notícias de assassinatos de funcionários do SPI. A percepção de ameaça que o indígena vivo causava continuava.

Apesar de tais perspectivas apontarem para uma sintonia entre o Império e a República, não se pode esquecer que o contexto social era outro, fazendo-nos encontrar também descontinuidades. Quando Cassiano Ricardo e Mário de Andrade publicam respectivamente Martim Cererê e Macunaíma ou quando Tarsila do Amaral titulou sua obra como Abaporu, eles estavam destacando os indígenas e de modo distinto do que fora feito até ali. Eles operaram um deslocamento, pois em seus trabalhos, mesmo ficcionais, o 
índio deixava de ser alegoria do Estado para se tornar suporte da cultura nacional e viabilizar o entendimento do 'ser brasileiro'. O movimento modernista apresentava novas discussões sobre a brasilidade e, nelas, os indígenas assumiam outro papel.

O movimento não foi uníssono e o Nhengaçu Verde-Amarelo, de Cassiano Ricardo, manteve uma imagem servil e modelar do índio, ironicamente chamado de índio de 'tampa de lata de biscoito', algo sem vida. Entretanto, aqueles que estavam sintonizados ao slogan de Oswald de Andrade - 'Tupi or not tupi, is the question' - transformavam perspectivas: a antropofagia, repudiada pelo cristianismo, deixava de ser marca negativa para se tornar alicerce do ser brasileiro, um povo capaz de digerir as culturas alheias, fugindo à cópia de modelos europeus. A ancestralidade indígena deveria ser matriz da identidade brasileira.

O movimento artístico não caminhou sozinho e algumas interpretações históricas e sociológicas sobre o Brasil, como as produzidas por Gilberto Freyre e Sergio Buarque de Holanda, também mudaram o lugar dos indígenas. Suas obras se referiam ao passado, à colonização, mas não era a alegoria que vinha à tona, eram povos com etnômio e experiências que possuíam história e tradição antes da chegada dos portugueses e construíram a história com ou contra o português.

Essas rearticulações não ficaram restritas ao mundo acadêmico, ganhando espaço público, e com o início do governo de Vargas receberam apoio, pois dada a aproximação do presidente a tais artistas e intelectuais, foi-se consolidando, através da educação e da cultura, a ideia de um Brasil mestiço. Uma nova imagem que dialogava com as prerrogativas governamentais através do SPI: a meta de incorporar a "essência indígena" no todo nacional.

O governo de Vargas foi longo e oscilante, o que não deixou de ter influência no SPI que, por exemplo, ao longo da década de 1930, passou por várias transferências de Ministérios. Vale um detalhamento.

Logo após a Revolução de 30, o SPI foi transferido do Ministério da Agricultura - que, inclusive, dava lastro à sigla inicial, onde Localização de Trabalhadores Nacionais se referia à transformação dos indígenas em camponeses - para o recém-criado Ministério do Trabalho, Indústria e Comércio. A importância de tal Ministério na política de Vargas poderia sugerir uma atenção especial ao projeto de incorporação dos indígenas. Porém, como junto à mudança houve uma diminuição do orçamento do Serviço de Proteção ao Índio, há dúvida sobre seu significado.

Em 1934 houve nova transferência de pasta e, saindo do Ministério do Trabalho, o SPI passou ao Ministério do Exército, alocado na Divisão de Fronteiras. Em 1936 cria-se um novo Regimento para o SPI, no qual é enfatizada a 'nacionalização dos silvícolas'. Em 1939, mais uma mudança: além de voltar à órbita do Ministério da Agricultura, há aumento de orçamento e criação do Conselho Nacional de Proteção ao Índio, sob o comando de Rondon. É possível, então, supor que permaneciam os 
pressupostos da integração nacional através da transformação dos indígenas em trabalhadores agrícolas, mas estavam sendo articulados à outra preocupação do governo Vargas, justificando até o período no Ministério do Exército: a ocupação e colonização do território nacional.

Essas informações mais detalhadas do governo Vargas servem para avaliar algumas alterações no contraste com a Primeira República. Naquela, os indígenas permaneceram como estranhos ao mundo moderno da Belle Époque carioca e os esforços iniciais do SPI ratificaram imagens de violência. Ao pensar colonização e ocupação do território, os indígenas voltam a ocupar o horizonte como instrumentos de controle do território, como chegaram a ser utilizados no período colonial. Há, assim, independentemente de sua 'civilização' ou não, uma perspectiva positiva para ele no quadro nacional.

Em 1940, o SPI mantinha firme sua intenção inicial: "Não queremos que o índio permaneça índio. Nosso trabalho tem por destino sua incorporação à nacionalidade brasileira, tão íntima e completa quanto possível" (GARFIELD, 2000 p.18). Mas naquele momento tal incorporação estava em sintonia com um contexto diferenciado: o ideal de "um todo orgânico' da ditadura varguista. Essa organicidade aspirada pretendia proporcionar serviços de educação e saúde, além de redes de comunicação e transporte aos indígenas e sertanejos, o que consolidaria a nação e atualizaria o projeto de fixação do homem à terra, convertendo aqueles grupos em cidadãos produtivos.

Para expor o posicionamento governamental e consolidar uma imagem pioneira e impetuosa do presidente, o Departamento de Imprensa e Propaganda do Estado Novo (DIP) arquitetou uma viagem de Vargas a uma aldeia de indígenas Karajá na Ilha do Bananal, em Mato Grosso. A mística de ser o primeiro presidente a visitar uma área indígena foi conectada à ideia de ousadia, comparada às expedições bandeirantes, e serviu para divulgar o projeto da "Marcha para o Oeste", lançado em 1938.

Um cinegrafista do DIP acompanhou Vargas, filmando imagens que o regime autoritário nacionalista procurou tornar relíquias: indígenas vigorosos, emblemáticos da força inata dos nativos brasileiros; o 'tradicionalismo' das comunidades indígenas; a camaradagem entre indígenas e brancos; a bonomia do presidente, epítome do homem cordial brasileiro; o longo braço do Estado estendendo-se ao sertão para dar-Ihe assistência. (GARFIELD, 2000, p.15)

De um lado, a incorporação do indígena ao todo nacional era capturada e transformada em prol dos projetos de Vargas e as ações do presidente para com os indígenas assumiam uma face de redenção; de outro, novas imagens passavam a recobrir a iconosfera brasileira, não mais com índios assassinos, mas emblemas da força e da tradição brasileiras e a possibilidade de camaradagem entre indígenas e não-indígenas. 
Todavia, nem tudo segue o roteiro. Imagens positivas circulavam simultaneamente a outras que recordavam significados das palavras tapuia, botocudo e selvagem. Para a "Marcha", pacificar os Xavante que ocupavam Mato Grosso era urgente, pois suas alteridade e hostilidade representavam um obstáculo à ideia de nação e ao desenvolvimento econômico da área. Para resolver o impasse, foi realizada uma expedição de pacificação em 1941 e seu resultado funesto endossou a perspectiva de que o governo teria de agir: o líder da expedição, Genésio Pimentel Barbosa, e cinco assistentes foram assassinados a bordoadas.

Nova expedição foi lançada em 1942, e se tornou célebre tanto no quadro em que se realizava, como nos desdobramentos posteriores: a expedição Roncador-Xingu. O texto de abertura de sua portaria é claro na identificação de seus pressupostos e metas:

O coordenador da Mobilização Econômica, usando das atribuições que lhe confere o decreto-lei n. 4.750, de 28 de setembro de 1942, e devidamente autorizado pelo Exmo. senhor Presidente da república, considerando a necessidade de criar vias de comunicação com o Amazonas, através do interior do país; considerando a necessidade de explorar e povoar o maciço central do Brasil nas regiões cabeceiras do rio Xingu, atualmente das mais desconhecidas da terra: Considerando que esta exploração constitui um passo decisivo para a realização do programa do Governo, sintetizado na "Marcha para o Oeste", resolve:

I) - Organizar a Expedição Roncador-Xingu, com os seguintes objetivos: (ESTADÂO, 1943, com grifos meus)

Insubstituível foi o papel da imprensa no processo, auxiliando na valorização da expedição e na construção das ideias de necessidade e de urgência em ocupar o território brasileiro e pacificar os Xavante. É necessário indicar que a década de 40 no Brasil foi emblemática na consolidação da sociedade urbano-industrial e de uma 'cultura popular de massa'. Como balizamentos dessa consolidação pode-se citar a criação das companhias de cinema Atlântida (1941) e Vera Cruz (1943), além da intensa multiplicação do rádio no país, pois em 1944 existiam 106 emissoras e em 1950 elas passaram a 300. O meio impresso também apresentou uma alavancagem, que pode ser medida no crescimento das tiragens e da importação de papel, chegando mesmo à implantação de um grupo nacional de produção de papel em 1947, o Klabin. Como referência especial para a representação dos indígenas, há o aumento da tiragem da revista O Cruzeiro: em 1948 é de 300 mil exemplares e em 1952 é de 550 mil.

Esses dados são importantes quando sabemos que a Marcha para o Oeste rivalizou com a Segunda Grande Guerra no noticiário nacional. Jornais capitalizavam as histórias de indígenas assassinos, instigando a fantasia da população urbana. O Vale do Araguaia aparecia como uma região quase 
fictícia: terras habitadas por indígenas e animais e totalmente cobertas de selva. Deste modo vai se construindo um clima de vigor e mistério para as expedições, fazendo com que os leitores dos periódicos vissem os expedicionários quase como mártires e alimentassem sua curiosidade sobre aquele desconhecido. A declaração do ministro João Alberto ao jornal $O$ Estado de São Paulo, em 4 de junho de 1943 é testemunho:

No próximo dia 15 de julho partirá uma grande expedição para a Serra do Roncador, rumo às cabeceiras do rio Xingu, abrindo, pelo interior, o caminho que ligará a Amazônia ao resto do país. Leva essa expedição, que será comandada pelo coronel Flaviano Vanique, outras missões, de povoamento, de colonização, de exploração das riquezas naturais e das possibilidades de vida nesse pedaço enorme, que é a maior área desconhecida do mundo, mais desconhecida, mesmo, que as próprias zonas vizinhas ao Himalaia. (ESTADÃO, 1943, com grifo meu)

Em prol da Marcha, ora se apresentava os indígenas com valor, ora com temor. Mas o que acontecia no Brasil dialogava com o mundo e, com o fim da Segunda Guerra Mundial, as impressões sobre os povos indígenas foram profundamente afetadas.

A crítica à razão moderna ocidental era antiga, mas as reflexões do pós-guerra estabeleceram uma fissura ideológica e moral na percepção de superioridade da 'civilização ocidental', havendo uma compleição para a aceitação do valor do outro. Essa ambiência ocorria de modo espontâneo em função do horror generalizado diante das ações do nazismo contra judeus, ciganos, etc., mas também de modo direcionado, com organismos internacionais se mobilizando para criar novas referências. Exemplar é o caso da ONU e seu braço para a educação, a UNESCO. Criada em 1945, a ONU teve como princípio promover a cooperação internacional e evitar conflitos como o que acabara de ocorrer e sua agência, para garantir a paz no mundo através da educação, ciências e informação, passou a se realizar em 1946 pela UNESCO. É ela que, em 1952, no desejo de embasar cientificamente uma postura antirracista, convida intelectuais para produzirem brochuras que seriam publicadas no formato de coleção e distribuídas gratuitamente. Nomeada $A$ questão racial diante da ciência moderna, é para essa coleção que Claude Lévi-Strauss escreve o ensaio Raça e História, texto marcante na antropologia que pode ser tido como bandeira em favor da diversidade cultural e social.

No caso do Brasil, a disposição internacional seguia um movimento de valorização do indígena como matriz do nacional. Retomada do Indianismo do século XIX? Sim e não, no interessante jogo das temporalidades históricas. É inegável que a associação entre indígenas e nação forjada no Império e manipulada pela imprensa durante toda a Primeira República, acomodava certa familiaridade na geração da década de 50 . Porém, não se 
pode supor a permanência das interpretações dessa associação, afinal, no mínimo, um elemento alterava em profundidade a percepção dos brasileiros: falava-se de índios vivos.

A historiografia é enfática em identificar o Império do Brasil atento em assegurar o território e a República em construir a nação. Ao se considerar essa premissa, de imediato certos dados mudam, pois os indígenas pretéritos e mortos do Império passavam a ser aqueles presentes e vivos da República, questão que, se não ficou chancelada na Carta de 1891, não deixou de ocupar as discussões na Constituinte, nos primórdios da República.

Não apenas. A criação do Serviço de Proteção aos Índios e o movimento modernista trouxeram outra configuração para a associação com o nacional. No caso do SPI, ainda que o propósito fosse civilizatório e transformador do indígena em algo que não ele mesmo, passou a ser imperativa a defesa de sua vida, o que nem de longe era questão no Império. No caso do modernismo, construiu-se um valor às culturas nativas, afirmando-se que o brasileiro da época era ele também indígena, assim como africano e europeu. Reelaborava-se o ser brasileiro. Como visto, na academia, Gilberto Freyre e Sergio Buarque de Holanda; na literatura, Mário e Oswald de Andrade; nas artes plásticas, Tarsila do Amaral, são alguns dos nomes que materializaram significações muito diferentes daquelas do XIX, já que os nativos estavam incorporados em cada brasileiro.

Essa mudança estabeleceu impasses diferentes, pois mesmo quando vistos como atrasados e primitivos, os indígenas vivos passavam a ser uma espécie de acervo que deveria ser preservado e cuidado para que o brasileiro pudesse se reconhecer. Eliminá-lo seria como eliminar a possibilidade de investigar a si mesmo. Não foi pensamento hegemônico na época, mas era uma reflexão de fácil acesso que modificava as compreensões anteriores e que passava a ser compartilhado por uma elite letrada detentora de influência.

Quando realizadas as primeiras expedições ao interior do país na década de 40 e o próprio presidente da República foi retratado ao lado de indígenas, foram lançados fios de referências que podiam ser costurados no tempo e gerar uma empatia e proximidade genérica entre indígenas e nãoindígenas, o que foi aumentando gradativamente com a imprensa, as declarações de sertanistas, os trabalhos de antropólogos, de médicos e de jornalistas que entraram em contato com as populações indígenas.

Os dados até aqui expostos já sustentam historicamente mudanças que poderiam (e foram) potencializadas pela expedição Roncador-Xingu, mas elas dialogaram com experiências que iam muito além das fronteiras do Brasil. Enfatizo três delas: o I Congresso Indigenista Interamericano, o crescimento acadêmico das Ciências Sociais (notadamente a antropologia) e os valores e ideias semeados no pós Segunda Guerra Mundial. 


\section{Anos 40 e 50: transformações}

Em 1940, em meio à guerra, ocorreu no México o l Congresso Indigenista Interamericano. Derivado da pauta da Conferência Internacional Americana de 1938 no Peru, o congresso foi proposto na intenção de se criar um Instituto Interamericano pois a questão indígena foi compreendida como algo continental. Ele foi fundante por oficializar uma declaração de princípios para sustentar direitos e proteção a todos os indígenas, enfatizando seu valor histórico e cultural, e por aglutinar além de militantes em prol dos interesses dos indígenas, os próprios indígenas. O dia 19 de abril, inclusive, foi escolhido para data comemorativa do índio em função de ter sido a data do início da participação deles no evento.

Importa menos que, mesmo o Brasil sendo um dos países participantes, Vargas só tenha assinado o decreto para a data comemorativa depois de outros países, em 1943 (coincidentemente (?) no mesmo ano em que iniciava expedição Roncador-Xingu), pois mais vale observar que havia uma mobilização internacional pró indígena e ela definia linhas de ação para valorização dos povos indígenas aos olhos dos não-indígenas, linhas essas que se acomodavam confortavelmente com as ideias do modernismo.

Além da movimentação na América, na Europa - num outro lugar e de outra maneira -, os indígenas também conquistaram uma visibilidade positiva. Especialmente na França - em função de Lévi Strauss - a disciplina antropologia ganhou força e notoriedade: o estruturalismo afirmou a existência de uma estrutura particular a cada cultura, rompendo com a ideia de um escalonamento entre os diferentes povos que definiam uma inferioridade aos povos indígenas.

A teoria sozinha é transformadora de perspectiva, mas poderia não ter alcançado de modo amplo a sociedade, caso estivesse restrita ao pequeno mundo da pesquisa e da universidade. Não foi o caso. As premissas da antropologia francesa circularam em espaços mais amplos e variados, a começar pelo citado folheto Raça e História de Lévi-Strauss, que foi distribuído gratuitamente pela UNESCO, multiplicando reflexões sobre o valor da diversidade racial.

Existem ainda desdobramentos menos óbvios que, apesar de se aportarem na academia, ultrapassam-na, chegando a diferentes órbitas na sociedade, como a economia, através da abertura de postos de trabalho. A legitimidade social da disciplina dará fôlego à criação de cursos (graduação e pós graduação) e novas instituições - como o caso do Museu do Índio -, mas também se infiltrará em antigas instituições como o SPI, onde os antropólogos formados se unirão aos sertanistas, intervindo, portanto, nas políticas públicas.

O último destaque escolhido para indicar transformações internacionais que se associavam ao que ocorria no Brasil são as ideias e os valores que se espraiaram no mundo através da comoção que o avanço dos 
meios de comunicação garantiu. Liberdade, democracia, diversidade e modernização tornaram-se vetores no chamado mundo ocidental.

Não se pode dizer que o holocausto diga diretamente de indígenas americanos (ainda que a teoria ariana certamente os desqualificasse), mas a vitória aliada consolidou argumentos contra a intolerância e a discriminação de povos, abrindo, desse modo, horizontes de compaixão e simpatia para outros grupos e populações, além daqueles diretamente atingidos pelo nazismo.

Uma predisposição favorável a alteridades populacionais conversava com a defesa da liberdade e da democracia, manifesta em evidente oposição ao totalitarismo. Considerando que as bases das duas estão na diferença, no reconhecimento da diferença, pode-se imaginar que os anseios políticos também amparavam essa predisposição de acolhimento a partes invisibilizadas da população brasileira. Predisposição facilitada porque, no que diz respeito aos indígenas, sua oficial participação na república se colocava muito mais no campo das ideias, sem a vivência de possíveis dificuldades, sem exigir muitos esforços de deslocamentos cognitivos por parte dos não-indígenas, pois ainda eram poucos os indígenas urbanos ou aqueles com voz.

Tal contexto permite uma estranha composição que fora inimaginável no Império: a associação entre positivação dos indígenas vivos e a modernização. Na segunda metade do XIX, quando a imigração europeia foi intensa, o café avançou para o interior e a estrada de ferro era símbolo do progresso, ninguém se importaria em matar indígenas no processo. Mas agora já não seria tão simples com as falas em prol da tolerância entre povos e nações e a atuação de décadas do SPI em defesa da vida dos indígenas.

Porém, por outro lado, no pós-guerra

se explicita um conjunto de ideias-força que anima a política de velhos e novos Estados. Assim, o termo 'desenvolvimento' penetra no vocabulário econômico, político e jornalístico e empolga estadistas, de particular nas novas nações. O crescimento econômico acelerado seria a chave da redução das desigualdades intra e internacionais. (GUIMARÃES, 2001, p.157)

Combinação confusa entre um olhar generoso para com os indígenas e uma modernização que se identificava à urbanização e à industrialização, mas era pano de fundo dos anos 50, na exata expressão da fotografia de Jean Manzon aliada ao texto de Rachel de Queiroz.

Conhecido por levar literalmente o lema "mostrar o Brasil aos brasileiros", o fotógrafo francês Jean Manzon foi, ao lado de outros fotógrafos como Henri Ballot e José Pinto, um pioneiro que revelou as diversas faces dos indígenas xinguanos. Observem a tensão: o 'mostrar' precisava da tecnologia da máquina fotográfica e do avião, mas 
simultaneamente se forjava na percepção de que o Brasil 'de verdade' existia nos confins inacessíveis e era povoado por indígenas.

Manzon chegou ao Brasil em 1941, depois de trabalhar no jornal France Soir, na revista Paris-Match e para o Serviço Cinematográfico da Marinha Francesa. Quando chegou, atuou no Departamento de Imprensa e Propaganda (DIP). Porém, entre 1943 e 1952 fotografou para a revista $O$ Cruzeiro. A seu serviço, viajou diversas vezes ao centro-oeste, sempre acompanhado do repórter David Nasser, e foi em uma dessas viagens que registrou a imagem citada por Raquel de Queiroz.

No início do século $X X$, as atividades sertanistas dos militares que integravam a Comissão de Linhas Telegráficas e dos funcionários do SPI foram também divulgadas em matérias jornalísticas com imagens, mas não podemos dizer que a atividade de Jean Manzon era a mesma: o contexto, a imprensa e os resultados eram outros.

O Malho, revista ilustrada de sátira política que circulou entre 1902 e 1954, apresentou várias manchetes e reportagens sobre os indígenas ao longo de sua existência. Em 1911, as primeiras incursões do SPI foram mote de severa crítica e de ridicularização, atestando ingenuidade e tolice do órgão diante dos 'bárbaros xavantes' ou 'selvícolas', que a todos matavam. As limitações técnicas dos periódicos - notadamente na impressão de fotografias -, a menor circulação dos mesmos, o menor número de brasileiros alfabetizados, o fato do SPI estar no início de suas atividades e interferir em práticas tradicionais de extermínio indígena, entre outros fatores, enfim, todo um conjunto de dados torna impossível equivaler as divulgações das expedições do início com as de meados do século. Enquanto as primeiras publicizavam dúvida sobre a ação governamental e barbarizavam os indígenas, as últimas legitimavam os sertanistas e criavam compaixão e dignidade para os povos originários.

Mais uma vez a Segunda Guerra Mundial foi expoente para essa transformação. Durante seu processo e para seu registro e divulgação, houve um aprimoramento técnico - fotografia, filme, impressos - além de um desenvolvimento teórico sobre mídia - obrigatório citar Joseph Goebbels -, qualificando artefatos e estratégias de comunicação. Para a análise das reportagens de $O$ Cruzeiro importa destacar o uso da emoção, foco dos estudos nazistas nas práticas de propaganda, e que constituiu suporte para a realização de enredos romanceados, capazes de envolver o leitor através da elaboração dos textos e da diagramação que, pensada sobre recentes parâmetros e possibilidades técnicas, estabelecia na leitura de imagens um ritmo, catalisando no leitor sensações que iam do risco e aventura à proximidade e conhecimento, como um frisson que vai sendo domesticado. Ao mesmo tempo, repórteres e fotógrafos apareciam como heróis, perspectiva oposta à dos funcionários do SPI, que eram vistos como tolos. Ao fim e ao cabo, inventava-se uma familiaridade entre conteúdo e leitor que acabava por comprometer não-indígenas com a vida dos indígenas no Brasil. 
A revista $O$ Cruzeiro e seu fotógrafo, Jean Manzon, inauguraram um novo modo de fazer fotorreportagem no Brasil, criando uma tensão interessante entre distante e próximo; entre passado e presente; entre bom e mau, mas, sobretudo, alimentando interesses múltiplos, capazes de acolher o imaginário de crianças, adultos e idosos, daquele que seria antropólogo ou sertanista, daquele que defendia o nacional contra o imperialismo, da gente comum que acompanhava as expedições como se fosse um folhetim.

Nasser e Manzon, além de Jorge Ferreira, Henri Ballot, Arlindo Silva, José Medeiros e outros, 'descobriram'o Brasil para os leitores. Com a ambição de serem intérpretes do Brasil, se envolviam com os problemas nacionais. Entretanto, os jornalistas de $O$ Cruzeiro produziram estereótipos sobre os sertanistas e os indígenas do Brasil Central. (...) jornalistas produzem reportagens impondo categorias de forma performativa, fazendo existir mundos sociais através das matérias publicadas. (FREIRE, 2005 p.43, com grifo meu)

Sim, eles também produziram estereótipos, mas que contrastavam ou desdiziam outros que haviam acompanhado as percepções de não-indígenas desde tempos imemoriais. Uma disputa entre representações ocorria em 'praça pública', na ágora onde se definiam o que pensar sobre e o que fazer com os indígenas.

Reuni referências que, desde o início do século $X X$, trouxeram deslocamentos nas representações indígenas no Brasil, tal como o obrigatório resguardo da vida - com a criação do SPI -, a valorização como matriz nacional no âmbito acadêmico e no artístico - especialmente com o modernismo -, a reinterpretação deles como amigáveis feita pela propaganda varguista - ainda que para dar sustentabilidade para seu gradual desaparecimento na 'essência nacional'. Reuni referências internacionais que caminharam simultaneamente a certas ações, especialmente a partir da Segunda Guerra Mundial. Materiais que, agora, podem ser articulados com eventos da década de 1950 e apontarem para o que considero a virada representativa que informa ainda hoje as relações entre indígenas e nãoindígenas.

Ícone do trabalho com indígenas no Brasil, a trajetória de Darcy Ribeiro será instrumento para acompanhar tanto os discursos da revista $O$ Cruzeiro como as políticas públicas do desenvolvimentismo e organizar o argumento.

Nascido em 1922 em Montes Claros (MG), mudou para Belo Horizonte para fazer faculdade de medicina, mas a experiência universitária o fez trocar o curso e em 1946 diplomou-se em Ciências Sociais pela Escola de Sociologia e Política de São Paulo, com especialização em antropologia. Logo no ano seguinte ingressou como etnólogo no SPI, de onde saiu apenas em 
1956 para lecionar na cadeira de Etnologia e Língua Tupi na Faculdade de Filosofia da Universidade do Brasil.

Dirigindo a Seção de Estudos do SPI, Darcy cria em 1953 o Museu do Índio e o "Curso de Aperfeiçoamento em Antropologia Cultural" para formar mais etnólogos e estender as pesquisas sobre indígenas no Brasil. No mesmo ano, ocorre a $1^{\text {a }}$ Reunião Brasileira de Antropologia que, tendo como presidente de honra Roquette Pinto (representante do Brasil no I Congresso Indigenista Interamericano), é esteio para a criação da Associação Brasileira de Antropologia em 1955. Ainda em 1953 é criado o Parque Nacional do Xingu, que pode ser considerado o primeiro passo na materialização de teorias acadêmicas subsidiando políticas públicas para os indígenas, pois a partir da argumentação de Darcy Ribeiro e Eduardo Galvão, sua demarcação levou em conta a ampliação do conceito de território indígena: foram incorporadas a perambulação tradicional, a imemorialidade, a integridade ecológica e o crescimento demográfico, ao que antes era definido apenas através da capacidade produtiva da comunidade. Como afirma Mércio Pereira Gomes, "a partir da década de 50, especialmente com a criação do Museu do Índio em 1953, é que a antropologia passa a ter um papel mais relevante na renovação do ideal positivista rondoniano" (GOMES, 2003, p 434).

O que esse brevíssimo perfil aponta? De imediato o crescimento institucional da antropologia e sua interferência nos projetos públicos, mas também uma conexão entre a academia e a sociedade, através do Museu do Índio, estabelecendo um acesso completamente diferenciado para a população em geral, pois a curadoria acadêmica na exibição de objetos foi oportunidade para diferentes olhares e relações, além de trazer a chancela da ciência em época de afã modernizador. A médio prazo, a formação de antropólogos inspira a proliferação de tudo isso.

Esse proliferar de referências é um dos pontos importantes para a virada na representação dos indígenas que acredito ter ocorrido nos anos 50 , pois ela irá viabilizar um compartilhamento extensivo do que acontecia. $\mathrm{Na}$ década anterior, o rádio já alcançara largos patamares para o nacional, mas a acelerada qualificação da mídia impressa, do cinema e a inauguração da televisão em 1950 catapultaram para bem mais longe qualquer mudança social. Uma sociedade de massa se instaurava e o consumo não era apenas de bens materiais: havia caminho para disseminação do que se fazia e dizia na capital do país, assim como a capital podia capturar os outros Brasis que apareciam.

A visita de Vargas aos Karajá, a expedição Roncador-Xingu e mesmo a criação do Parque Nacional não ativaram somente informações que poderiam reverter estereótipos seculares. Os textos de aventura e as imagens da floresta que os meios de comunicação apresentaram certamente incentivaram a permanência de interpretações seculares, numa ênfase do contraste entre mata/cidade ou entre o dito primitivo/civilizado, afinal 
Entre 1950 e 1979, a sensação dos brasileiros, ou de grande parte dos brasileiros, era a de que faltava dar uns poucos passos para finalmente nos tornarmos uma nação moderna. Esse alegre otimismo, só contrariado em alguns rápidos momentos, foi mudando a sua forma. Na década de 50, alguns imaginavam até que estaríamos assistindo ao nascimento de uma nova civilização nos trópicos, que combinava a incorporação das conquistas materiais do capitalismo com a persistência dos traços de caráter que nos singularizavam como povo: a cordialidade, a criatividade e a tolerância. (MELLO \& NOVAIS, 1998, p.560)

Mas, a singularidade do povo conversava cada vez mais com os povos originários - em oposição ao acesso à modernização, seria justamente aquilo de comum entre nações, aquilo que as igualaria e não o que as particularizava. Entrelaçamento confuso, quase paradoxal, mas não apenas possível como efetivamente vivido, como expressa o fragmento de Rachel de Queiroz. A compaixão da escritora diante do "coração bárbaro" enfrentando "os engenhos mais modernos da civilização". Era o bom bárbaro.

Não faltaram contradições, um cabo de guerra no qual o desenvolvimento e a modernização anunciavam o fim inevitável das populações indígenas e o nacionalismo do pós-guerra, que carregava a tradição modernista nas costas, convivia com o fantasma do imperialismo e trazia, no bojo de uma experiência democrática, um aprendizado sobre direitos do homem que se universalizavam e multiplicavam, todos trazendo um promissor horizonte para os indígenas.

O indígena na "essência nacional" do modernismo e do Estado Novo já foi apresentado, assim como a revista $O$ Cruzeiro e o crescimento da antropologia no Brasil deram sustentação ao indígena para que ele ocupasse, aos olhos públicos, o lugar do nacional como particularidade, como o que deveria ser defendido na pasteurização da sociedade de consumo. Cabe dizer dos direitos do homem como expressão dos valores compartilhados no pós-guerra.

Em A era dos direitos, Norberto Bobbio (1992) aponta as conexões entre mudança social e nascimento de novos direitos. Afirmando que os direitos são um fenômeno social e histórico, ele analisa alguns que considera terem alterado paradigmas no século XX e apresenta o pós Segunda Guerra Mundial como um momento em que a demanda e aquisição de direitos expressou a revisão de perspectivas.

Para ele, a Segunda Guerra se tornara um divisor no âmbito do reconhecimento de direitos do homem. Antes dela, o reconhecimento era nacional, mas ao término ele passou à esfera internacional e, portanto, considerado algo que diz respeito a todos os povos. Essa internacionalização sustenta um dos dois caminhos que Bobbio identifica existirem para que possamos compreender o direito e sua aplicação: a universalização. 
As lutas por independência em países africanos e asiáticos atrelados às políticas colonialistas ganharam força no pós-guerra não só pelo enfraquecimento dos países europeus partícipes da guerra, mas por essa universalização dos direitos, tornando incompatível que potências signatárias da Declaração de Direitos Humanos, promulgada pela ONU em 1948, mantivessem colônias.

Além da publicização da incongruência, a cobertura midiática das lutas trouxe visibilidade internacional a povos que a história ocultava e que a coetânea defesa da liberdade e da democracia tornava conhecidos e valorosos. Foram experiências históricas impactantes para quem vivia os chamados Anos Eufóricos, consolidando sentidos simultâneos e antagônicos: de um lado (interessante para o argumento aqui defendido), a visibilidade de alteridades e o reconhecimento de voz; de outro, o receio por parte de grupos que se beneficiavam com a exploração.

O outro caminho identificado por Bobbio para o direito no pós-guerra foi o sentido de multiplicação, pois os bens merecedores de tutela teriam aumentado, a titularidade de direitos típicos teria sido estendida a sujeitos diversos do homem e, por último, porque o homem teria deixado de ser visto como um ente genérico, passando a ser visto na sua especificidade.

$\mathrm{O}$ aumento dos bens merecedores de tutela refere-se aos direitos políticos e sociais, somados aos direitos de liberdade consagrados pela Revolução Francesa. A extensão da titularidade a sujeitos diversos do homem se refere ao fato de o direito não atender apenas indivíduos singulares, alcançando sujeitos diferentes como a família, as minorias étnicas e religiosas, ou mesmo a humanidade no seu conjunto. Mais: até sujeitos diferentes do ser humano passaram a ter direitos, como é o caso dos animais.

Já a última tendência citada está ancorada na transformação da noção de indivíduo, que deixou de ser genérico e universal para ser visto em sua especificidade e diferença, ou seja, na ideia de que deveriam existir diferentes tratamentos, pois a mulher seria diferente do homem, a criança do adulto, o sadio do doente, etc.

Considero que tais direções são conteúdos chave para o argumento da virada na representação dos indígenas nos anos 50 e da permanência até hoje de certos parâmetros, especialmente porque o que poderia ser simples tendência no imediato pós-guerra, gradativamente foi se consolidando e ampliando, garantindo que os princípios norteadores dessas tendências mantenham hoje sua validade.

A extensão da titularidade de direitos a sujeitos diversos do indivíduo é estruturalmente importante para os povos indígenas, pois significa a viabilidade da propriedade coletiva. Entender que os direitos humanos não são apenas para indivíduos significa viabilizar a propriedade coletiva da terra, a propriedade intelectual coletiva ou a autoria coletiva, princípios fundantes de povos indígenas, mas experiências antes incompreensíveis no código iluminista. É um deslocamento teórico significativo, desconstruindo 
a matriz iluminista e ampliando enormemente o campo de possibilidade de pensar e ver o mundo.

A transformação da noção de indivíduo está na base da última tendência mencionada por Bobbio em seu texto, quando passam a ser consideradas as especificidades do indivíduo, reconhecidas as diferenças entre eles. Segundo Stuart Hall (2004), houve um processo grande de mudança, num gradual descrédito do indivíduo como entidade centrada, unificada e consciente. Primeiro a dimensão social teria se apresentado, questionando a autossuficiência do indivíduo; depois, uma crítica mais radical a esse modelo de unidade e coerência se realizara: o indivíduo não seria mais definido por sua biologia, mas por sua história, sendo composto, portanto, por identidades diversas, contraditórias, continuamente deslocadas. Em lugar do indivíduo genérico, ganhou lugar o indivíduo específico, o que pode ser averiguado nas cartas de direito chanceladas a partir do fim da guerra - como a Convenção sobre os Direitos Políticos da Mulher (1952); a Declaração da Criança (1959), a Declaração dos Direitos do Deficiente Mental (1971) e outras. Deste modo, a identidade singular passa a estar fundada na historicidade dos contextos vividos pelos sujeitos.

Essa direção jurídica, todavia, está presente em outras referências, algumas aqui apresentadas: o estruturalismo e a validação da diferença cultural, a disseminação do conceito antropológico de cultura, a defesa da diversidade e a crítica ao racismo são elementos e mobilizações que assinalam com igual vigor um novo contexto potencializador de demandas. O homem universal que ancorara a ideia de indivíduo se apresentou inviável no entendimento da diversidade de realidades e culturas.

Direções que atravessaram momentos delicados da história brasileira vieram a ter oficialidade no Brasil somente a partir da Constituição de 1988, quando, depois da ditadura, tornou-se admissível a existência de capítulos específicos para o meio ambiente; a família, a criança, o adolescente e o idoso; os índios. É preciso, porém, enfatizar que a consolidação de tais princípios não foi realizada da noite para o dia. Construindo uma trajetória, localizo o momento do pós-guerra - a década de 1950 - como a largada ou início de consideração de tais ideias, que foram gradualmente ampliadas e rearticuladas diante das situações.

Exemplo de rearticulação compulsória para os não-indígenas e que demanda novas reflexões foi o fim do decréscimo populacional indígena entre 1955 e 1965, quando as taxas de natalidade passaram a crescer e romperam as expectativas daqueles que apostavam em sua inexorável extinção. $\mathrm{O}$ inesperado acontecia.

\section{Conclusões}

A partir da década de 1960, situações criaram distintos arranjos e possibilidades. O movimento da contracultura, por exemplo, com lemas 
como 'faça amor, não faça guerra' - que censuravam a violência da Guerra do Vietnã -, acentuava a crítica ao capitalismo (com seu modo de vida) e o desprezo da razão moderna ocidental diante de outras racionalidades, bem como invadia a sociedade com o amor livre (enfrentando o modelo cristão e burguês de família e dando visibilidade a comportamentos como a poligamia), com religiões politeístas, chás, ervas e práticas terapêuticas orientais - apresentando alternativas antes desconhecidas e inimaginadas.

Antes, os movimentos de libertação na África animaram sensibilidades em defesa de nacionalismos e sujeitos silenciados. No fim dos anos 60, no contexto de contracultura, explode o movimento Black Power naquela que se tornara a potência com maior força no uso dos meios de comunicação. Personagens como Martin Luther King, Malcolm X e os Panteras Negras estenderam críticas e mobilizaram movimentos em diversas partes do mundo, numa contínua conquista e inclusão de grupos destituídos e inferiorizados.

O movimento ambientalista também cresceu no período: do lançamento da obra Primavera silenciosa, de Rachel Carson (1962), à ação da ONU nos anos 70 com o desenvolvimento de programas e conferências, o sentido de biodiversidade se alicerçou, dando passagem ao conceito de sociodiversidade, que ratificava o que já fora dito ser imprescindível à humanidade naquela brochura de Lévi-Strauss em 1952. As pesquisas na área ambiental também puderam ser solo para uma valorização genérica dos povos indígenas, numa recorrente comparação entre os usos que fazem da natureza e aqueles efetivados por não-indígenas.

E se tais conteúdos se referem a contextos internacionais - apesar de seus evidentes impactos na sociedade brasileira -, não se poderia deixar de fora a crescente mobilização indígena que ressignificou a palavra índio para sustentar seus interesses junto à sociedade envolvente e, através da regularização intensa na década de 1980 de Organizações Não Governamentais Indígenas, incorporou modos não-indígenas de associação e discussão interétnica para fazer valer suas demandas

Inúmeras situações se somaram no jogo contínuo de reordenações de sentido, mas alargaram visibilidade e legitimidade até as conquistas da Carta de 1988.

A disseminação da teoria antropológica no Brasil ocorre justamente quando estava em processo um planejado avanço para o interior do país na intenção de efetivar o desenvolvimento que era concebido apenas como urbanização e industrialização - e que inevitavelmente promoveria o contato com indígenas. Cobrindo os projetos governamentais como a expedição Roncador-Xingu, a imprensa de Assis Chateaubriand romanceia a vida indígena e envolve os não-indígenas em sua defesa atualizando a fórmula do "bom selvagem" ao qualificá-los como "sadios, apolíticos e não contaminados pelo vil metal”. O indígena passara a bom bárbaro, o coração selvagem que manteria a dignidade e força do brasileiro. 
A percepção do indígena como outro tem longa duração, mas a relação com essa alteridade não foi a mesma ao longo do tempo. Acredito que aquela fundada no pós-guerra (posteriormente desenvolvida) engendrou uma mudança importante, uma revisão de premissas que reconfigurou estruturalmente quem poderia ser o indígena a partir da autocrítica dos nãoindígenas, a partir da vivência do horror em escala internacional que expôs limites muito claros ao modo de ver e viver de antes da guerra. Até aquele evento, o valor estava no igual, no princípio iluminista do indivíduo, que garantiu conquista dos direitos de liberdade e a construção do mundo contemporâneo. Depois dele, a unidade se fragmentou, o valor foi deslocado para a diferença e ainda é o que orienta o século XXI. Antes ele era o 'bárbaro' que precisava ser domado, transformado em outra coisa que não ele mesmo. Hoje, caso sejam vistos como 'bárbaros' (e para muitos nãoindígenas eles são), aqueles que assim pensam terão, no mínimo, uma avalanche de discursos sobre a diversidade cultural, legitimando que os indígenas podem continuar sendo o que são. $\mathrm{E}$, apesar de toda e qualquer desqualificação, o senso comum do brasileiro - informado pela escola e fora dela -considera-o alicerce nacional seja como povo mestiço "que traz na alma traz na alma, quando não na alma e no corpo (...) a sombra, ou pelo menos a pinta, do indígena e do negro" FREYRE, 1987, p.283), como escreveu Gilberto Freyre, ou como o forte que manteve sua cultura apesar dos esforços para exterminá-la. Ele é o 'bom bárbaro', a força da tradição brasileira.

Representações de indígenas moradores das florestas (e só delas), despidos (e apenas assim) e primitivos (incapazes de manusear tecnologias ou saber em quem votar) atravessaram anos e persistem no século XXI. Mas hoje elas contrastam com o reconhecimento de que existem indígenas no presente e nas cidades, de que possuem culturas específicas e de que são sujeitos de direitos. 
Espaço Ameríndio

Referências Bibliográficas:

BANIWA, Gersen. "A conquista da cidadania indígena e o fantasma da tutela no Brasil contemporâneo", In: RAMOS, Alcida Rita (org.). Constituições nacionais e povos indígenas. Belo Horizonte: UFMG, 2012.

BANTON, Michel. A ideia de raça. Lisboa: Edições 70, 1979.

BOBBIO, Norberto. A era dos direitos. SP: Campus, 1992.

BRANDÃO, Carlos Rodrigues. Identidade e etnia: construção da pessoa e resistência cultural. São Paulo: Brasiliense, 1986.

CHARTIER, Roger. "Introdução. Por uma sociologia histórica das práticas culturais.”, In: A história cultural. Entre práticas e representações. Lisboa: Difel, 1990.

Constituição da República Federativa do Brasil, 1988.

DANDLER, Jorge. "Povos indígenas e estado de direito na América Latina: eles têm alguma chance"?, In: MENDEZ, J. E.. O’DONNELL, G.; PINHEIRO, P. S. (orgs.) Democracia, violência e injustiça. São Paulo: Paz e Terra, 2000.

DIMENSTEIN, Gilberto. "Massacre de índios", In: Democracia em pedaços. Direitos humanos no Brasil. São Paulo: Companhia das Letras, 1996.

DUPRAT, Deborah. "O Direito sob o marco da plurietnicidade/ multiculturalidade", In: RAMOS, Alcida Rita (org.). Constituições nacionais e povos indígenas. Belo Horizonte: UFMG, 2012.

FERNANDES, Eunícia Barros Barcelos. "Imagens de índios e livros didáticos: uma reflexão sobre representações, sujeitos e cidadania." In: ROCHA, Helenice; MAGALHAES, M. S.; REZNIK, L. (Org.) A história na escola: autores, livros e impressos. Rio de Janeiro: Editora FGV, 2009.

FREIRE, Carlos Augusto da Rocha. Indigenismo e antropologia. O Conselho Nacional de Proteção aos Índios na gestão Rondon (1939-1955). Dissertação de Mestrado. Rio de Janeiro: UFRJ/ MN/ PPGAS, 1990.

FREIRE, Carlos Augusto da Rocha. Sagas Sertanistas: práticas e representações do campo indigenista no século XX. Tese doutorado Antropologia social, PPGAS: Museu Nacional - UFRJ, 2005.

FREYRE, Gilberto. Casa-Grande \& Senzala. ed. Rio de Janeiro: José Olímpio, 1987. 
Espaço Ameríndio

GALVÃO, Maria Eduarda Capanema Guerra. A expedição Roncador-Xingu e a tarefa de ocupar, civilizar e urbanizar o Brasil. Dissertação História; CPDOC: Rio de Janeiro, 2014.

GARFIELD, Seth. "As raízes de uma planta que hoje é o Brasil: os índios e o Estado-Nação na era Vargas". Revista Brasileira de História, 2000, vol.20, no.39, p.13-36.

GOMES, Mércio P. "O caminho brasileiro para a cidadania indígena”, In: PINSKY, Jaime e PINSKY, Carla Bassanezi. História da Cidadania, São Paulo: Contexto, 2003.

GOMES, Mércio Pereira. Os índios e o Brasil. Petrópolis: Vozes, 1991.

GUIMARÃES, César. "Vargas e Kubistchek: a longa distância entre a Petrobrás e Brasília", In: CARVALHO, Maria Alice Rezende. A República no Catete. Rio de Janeiro: Museu da República, 2001.

HALL, Stuart. A identidade cultural na pós-modernidade. Rio de Janeiro: D P \& A, 9a. ed. 2004.

HARTOG, François. O espelho de Heródoto. Ensaio sobre a representação do outro. Belo Horizonte: UFMG, 1999.

HESPANHA, Antonio Manuel \& SILVA, Ana Cristina Nogueira da. "A identidade portuguesa", In: José Mattoso (dir.). História de Portugal, volume 4, Lisboa, Editorial Estampa, 1997.

KODAMA, Kaori Os filhos das brenhas e o Império do Brasil: A etnografia no Instituto Histórico e Geográfico do Brasil (1840-1860). Tese História; PUC-Rio; 2005.

KRENAK, Ailton. "O eterno retorno do encontro", In: NOVAES, Adauto. A outra margem do Ocidente. São Paulo: Companhia das Letras, 1999.

LEVI-STRAUSS, Claude. "Raça E História." Antropologia Estrutural Dois. Rio de Janeiro: Tempo Universitário, 1986.

LIMA, Antonio Carlos \& OLIVEIRA FILHO, João Pacheco. "Os muitos fôlegos do indigenismo", In: Anuário Antropológico, 1983.

LIMA, Antonio Carlos Souza. Um grande cerco de paz. Petrópolis: Vozes, 1995.

MARÉS, Carlos Frederico. "Da tirania à tolerância. O direito dos índios", In: NOVAES, Adauto (org.). A outra margem do ocidente. São Paulo: Companhia das Letras, 1999.

MARTINS, Ana Cecília Impellizieri de Souza Martins. Bem na foto: a invenção do Brasil na fotografia de Jean Manzon. Dissertação Mestrado História; PUC-Rio; 2007. 
Espaço Ameríndio

MELLO, João Manuel Cardoso de \& NOVAIS, Fernando. "Capitalismo tardio e sociabilidade moderna”, In: SCHWARCZ, Lilia Moritz (org.). História da Vida Privada no Brasil vol. 4. São Paulo: Companhia das Letras, 1998.

MENEZES, Maria Lúcia Pires. Parque Indígena do Xingu. Construção de um território estatal. Campinas: Unicamp, 2002.

MEYRER, Marlise Regina. Representações do desenvolvimento nas fotorreportagens da revista O Cruzeiro (1995 - 1957). Tese História; PUC-RS, 2007.

ORTIZ, Renato. A moderna tradição Brasileira. São Paulo: Brasiliense, 1988.

. Cultura brasileira e identidade nacional. São Paulo: Brasiliense, 1985.

PÉCAUT, Daniel. Os intelectuais e a política no Brasil. São Paulo: Editora Ática, 1990.

PORTARIA no.77, Coordenação de Mobilização Econômica. Disponível em: https://issuu.com/araujo49/docs/vanique1

QUEIROZ, Rachel. "O coração bárbaro do Brasil”, In: MANZON, Jean. Flagrantes do Brasil. Rio de Janeiro: Bloch Ed., 1956.

RAMOS, Alcida Rita. "Indigenismo: um orientalismo americano", In: Anuário Antropológico [Online], I | 2012.

SANTILLI, Márcio. Os brasileiros e os índios. São Paulo: SENAC, 2000.

SILVA, Aracy Lopes da \& GRUPIONI, Luís Donisete Benzi (orgs.). A temática indígena na escola. Novos subsídios para professores de 1o. e 2o. graus. Brasília: MEC/MARI/ Unesco, 1995.

TACCA, Fernando de. "O índio na fotografia brasileira: incursões sobre a imagem e o meio". História, Ciências, Saúde - Manguinhos, Rio de Janeiro, v.18, n.1, jan.-mar. 2011, p.191223.

TACCA, Fernando de. "Rituaes e festas Bororo. A construção da imagem do índio como "selvagem" na Comissão Rondon", In: Revista de Antropologia, São Paulo, USP, 2002, V. $45 \mathrm{n}^{\mathrm{o}} 1$.

VIVEIROS DE CASTRO, Eduardo. A inconstância da Alma selvagem e outros ensaios de antropologia. São Paulo: Cosac-Naify, 2011.

ZIEGLER, Erica Deuberet PERRET, Geneviève. "L'autre, une construction permanent”, In: Nous autres. Genève: MEG, 2005. 
Espaço Ameríndio

Recebido em: 21/02/2020 * Aprovado em: 22/04/2020 * Publicado em: 11/09/2020

FERNANDES, Eunícia Barros Barcelos. O bom bárbaro e outras histórias. Espaço Ameríndio, Porto Alegre, v. 14, n. 1, p. 1-28, jan./jul. 2020 